In cooperation with the U.S. Army Corps of Engineers

Design and Compilation of a Geodatabase of Existing Salinity Information for the Rio Grande Basin, from the Rio ArribaSandoval County Line, New Mexico, to Presidio, Texas, 2010

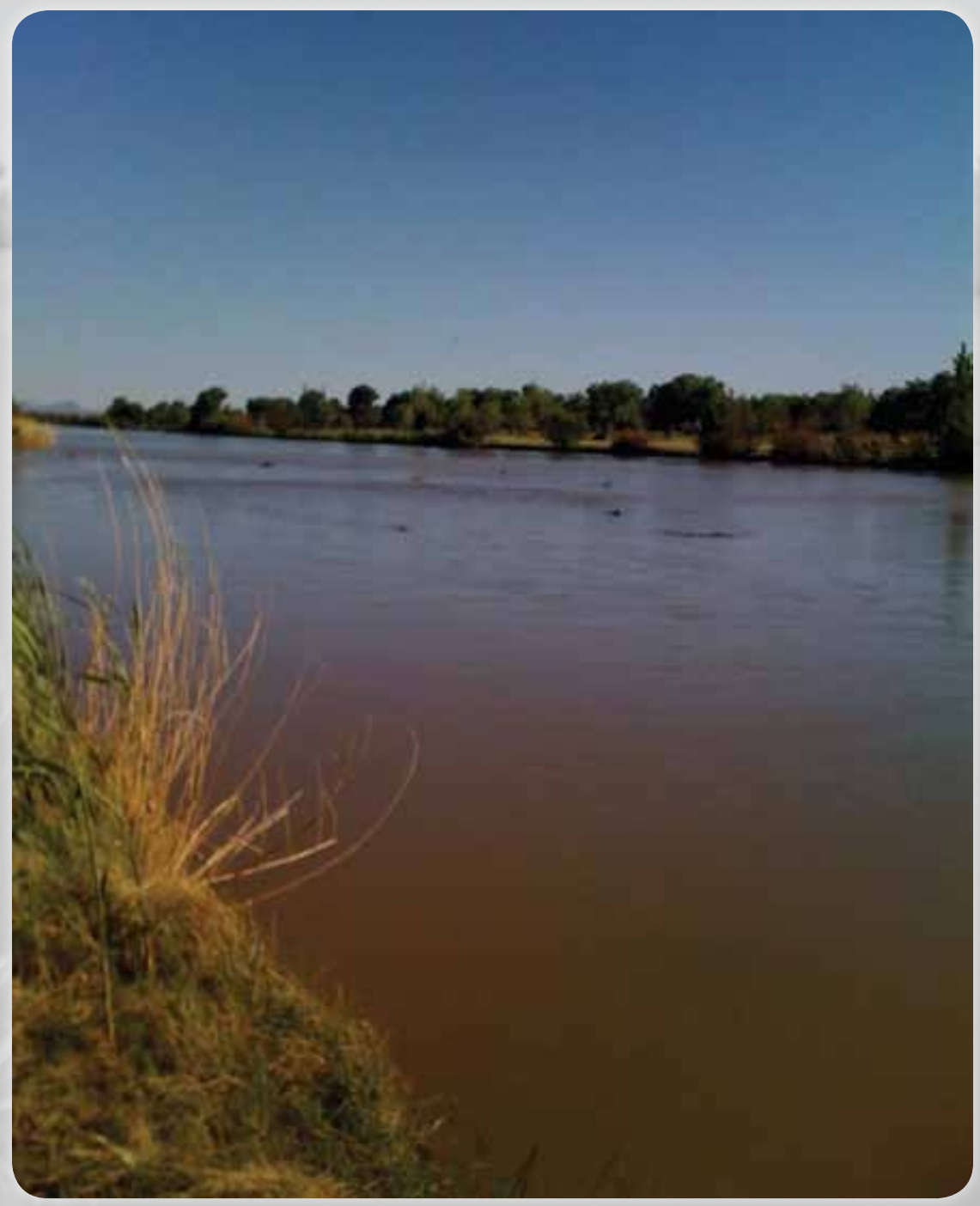

Data Series 499 
Cover: Upstream view of the Rio Grande near Ohara Road, Anthony, New Mexico, May 2010 (photograph by Julian D. Maltby). 


\section{Design and Compilation of a Geodatabase of Existing Salinity Information for the Rio Grande Basin, from the Rio Arriba- Sandoval County Line, New Mexico, to Presidio, Texas, 2010}

By Sachin D. Shah and David R. Maltby II

In cooperation with the U.S. Army Corps of Engineers

Data Series 499 


\section{U.S. Department of the Interior \\ KEN SALAZAR, Secretary \\ U.S. Geological Survey \\ Marcia K. McNutt, Director}

U.S. Geological Survey, Reston, Virginia: 2010

This and other USGS information products are available at http://store.usgs.gov/
U.S. Geological Survey
Box 25286, Denver Federal Center
Denver, CO 80225
To learn about the USGS and its information products visit http://www.usgs.gov/
1-888-ASK-USGS

Any use of trade, product, or firm names is for descriptive purposes only and does not imply endorsement by the U.S. Government.

Although this report is in the public domain, permission must be secured from the individual copyright owners to reproduce any copyrighted materials contained within this report.

Suggested citation:

Shah, S.D., and Maltby, D.R., II, 2010, Design and compilation of a geodatabase of existing salinity information for the Rio Grande Basin, from the Rio Arriba-Sandoval County line, New Mexico, to Presidio, Texas, 2010: U.S. Geological Survey Data Series 499, 24 p. 


\section{Acknowledgments}

The authors would like to thank Dale Doremus and Gregory Lewis of the New Mexico Interstate Stream Commission for providing valuable data and insight on the Rio Grande Basin; James Hogan of the University of Arizona for providing data; and members of the Rio Grande Salinity Management Coalition for their interest and involvement in developing the work plan for this project. 
Blank Page 


\section{Contents}

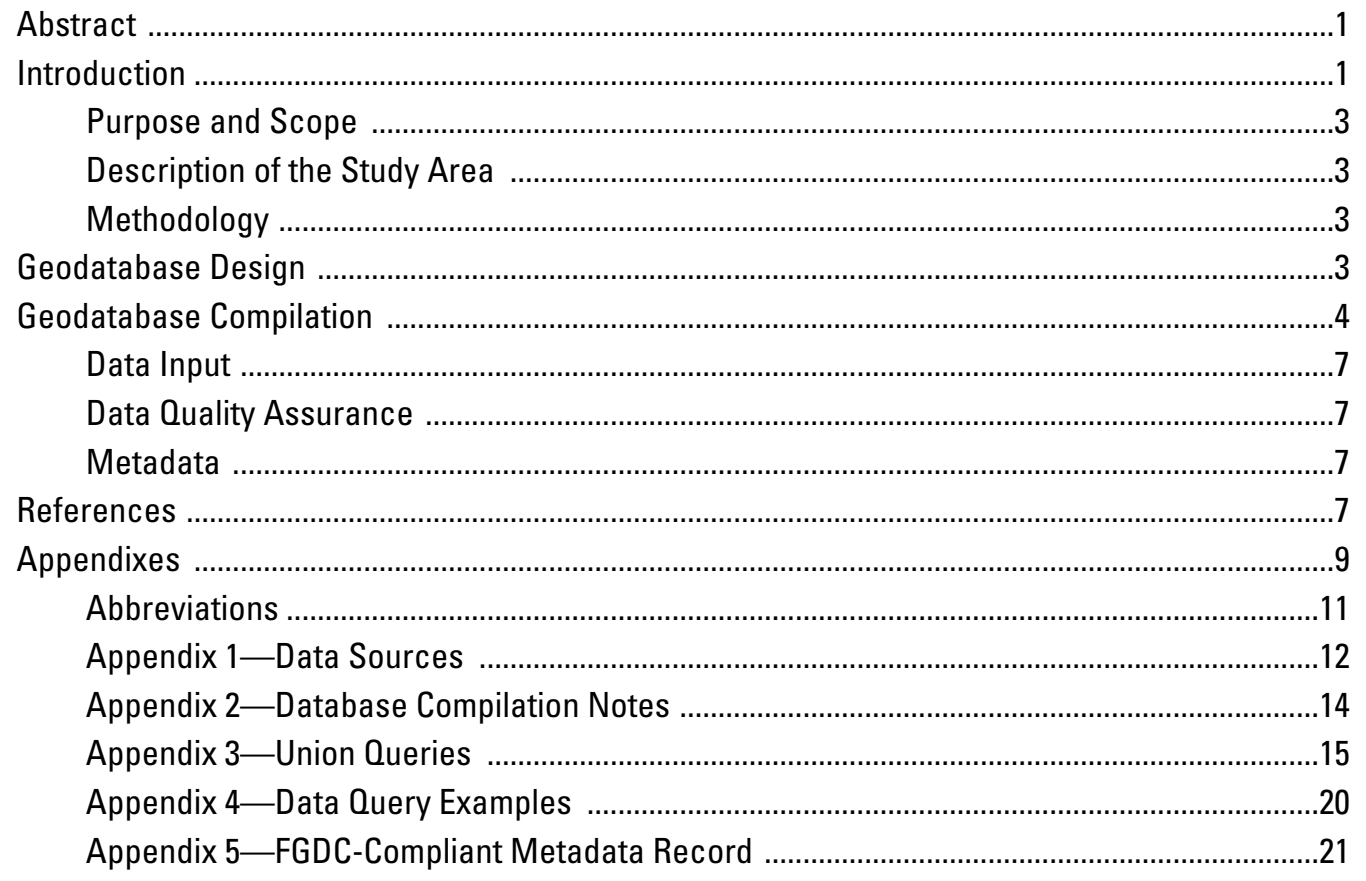

\section{Figures}

1. Map showing spatial extent of existing data for the Rio Grande Basin, from the Rio Arriba-Sandoval County line, New Mexico, to Presidio, Texas, 2010

2. Diagram showing relational tables in the geodatabase of water-quality information for the Rio Grande Basin, from the Rio Arriba-Sandoval County line, New Mexico, to Presidio, Texas, 2010

\section{Tables}

1. Description and definition of data compiled and entered into the geodatabase of water-quality information for the Rio Grande Basin, from the Rio Arriba-Sandoval County line, New Mexico, to Presidio, Texas, 2010

2. Sources of data compiled and entered into the geodatabase of water-quality information for the Rio Grande Basin, from the Rio Arriba-Sandoval County line, New Mexico, to Presidio, Texas 


\section{Conversion Factors, Datums, and Water-Quality Unit}

\section{Inch/Pound to SI}

\begin{tabular}{lcc}
\hline Multiply & By & To obtain \\
\hline mile $(\mathrm{mi})$ & Length & \\
\hline & 1.609 & kilometer $(\mathrm{km})$ \\
\hline square mile $\left(\mathrm{mi}^{2}\right)$ & Area & square kilometer $\left(\mathrm{km}^{2}\right)$ \\
\hline
\end{tabular}

\section{SI to Inch/Pound}

\begin{tabular}{lll}
\hline \multicolumn{1}{c}{ Multiply } & By & \multicolumn{1}{c}{ To obtain } \\
\hline & Length & \\
\hline kilometer $(\mathrm{km})$ & 0.6214 & mile (mi) \\
meter $(\mathrm{m})$ & 3.281 & foot (ft) \\
\hline
\end{tabular}

\section{Datums}

Vertical coordinate information is referenced to North American Vertical Datum of 1988 (NAVD 88).

Horizontal coordinate information is referenced to North American Datum of 1983 (NAD 83).

\section{Water-Quality Unit}

Concentrations of chemical constituents in water are given in milligrams per liter (mg/L). 


\title{
Design and Compilation of a Geodatabase of Existing Salinity Information for the Rio Grande Basin, from the Rio Arriba-Sandoval County Line, New Mexico, to Presidio, Texas, 2010
}

\author{
By Sachin D. Shah and David R. Maltby II
}

\section{Abstract}

The U.S. Geological Survey, in cooperation with the U.S. Army Corps of Engineers, compiled salinity-related waterquality data and information in a geodatabase containing more than 6,000 sampling sites. The geodatabase was designed as a tool for water-resource management and includes readily available digital data sources from the U.S. Geological Survey, U.S. Environmental Protection Agency, New Mexico Interstate Stream Commission, Sustainability of semi-Arid Hydrology and Riparian Areas, Paso del Norte Watershed Council, numerous other State and local databases, and selected databases maintained by the University of Arizona and New Mexico State University. Salinity information was compiled for an approximately 26,000-square-mile area of the Rio Grande Basin from the Rio Arriba-Sandoval County line, New Mexico, to Presidio, Texas. The geodatabase relates the spatial location of sampling sites with salinity-related waterquality data reported by multiple agencies. The sampling sites are stored in a geodatabase feature class; each site is linked by a relationship class to the corresponding sample and results stored in data tables.

\section{Introduction}

The Rio Grande Basin from the Rio Arriba-Sandoval County line, N. Mex., to Presidio, Tex. (fig. 1), an area of about 26,000 square miles, is characterized as arid or semiarid and has numerous natural sources of dissolved solids (Benke and Cushing, 2005). High concentrations of dissolved solids (also expressed as salinity) in this part of the Rio Grande Basin have been noted for almost 100 years (Stabler, 1911). The problems associated with high salinity are of growing concern for water-resource managers as rapid urban growth in cities along the Rio Grande in the United States and Mexico causes increased water demand and changes urban, agricultural, and environmental conditions and water uses.
For example, the quality of water in the Rio Grande is becoming increasingly important as more surface water is proposed for diversion from the river for potable and non-potable uses (Langman, 2009). Historically, high concentrations of salinity in this reach have been attributed to (1) reservoir evaporation, which increases the concentration of dissolved solids in the remaining water in storage; (2) displacement of shallow saline groundwater during irrigation, which subsequently contributes to irrigation return flow; (3) erosion and dissolution of natural mineral deposits containing high concentrations of dissolved solids ; and (4) inflow of deep saline or geothermal groundwater (Pillsbury, 1981; Allison and others, 1990, Moore and Anderholm, 2002; Philips and others, 2003).

The U.S. Geological Survey (USGS), in cooperation with the U.S. Army Corps of Engineers (USACE), compiled salinity-related water-quality information in a geodatabase for use in the development of a comprehensive baseline salinity budget for a part of the Rio Grande included in the overall study area of the geodatabase, the reach from San Acacia, N. Mex., to Fort Quitman, Tex. The geodatabase was designed as a tool for water-resource management and includes readily available digital data sources from the USGS, U.S. Environmental Protection Agency (USEPA), New Mexico Interstate Stream Commission (NMISC), Sustainability of semi-Arid Hydrology and Riparian Areas (SAHRA), Paso del Norte Watershed Council, numerous other State and local databases, and selected databases maintained by the University of Arizona and New Mexico State University. The geodatabase was designed so that any salinity-related water-quality data collected by an agency or university can be integrated into a single repository of salinity-associated data for the Rio Grande Basin. Despite many studies by numerous Federal, State, and local agencies and universities investigating salinity sources and possible mitigation strategies, water-quality data and the ancillary information associated with data collected during the course of these studies had never been compiled into a regional, comprehensive geodatabase for the Rio Grande Basin from the Rio Arriba-Sandoval County line, N. Mex., to Presidio, Tex. 


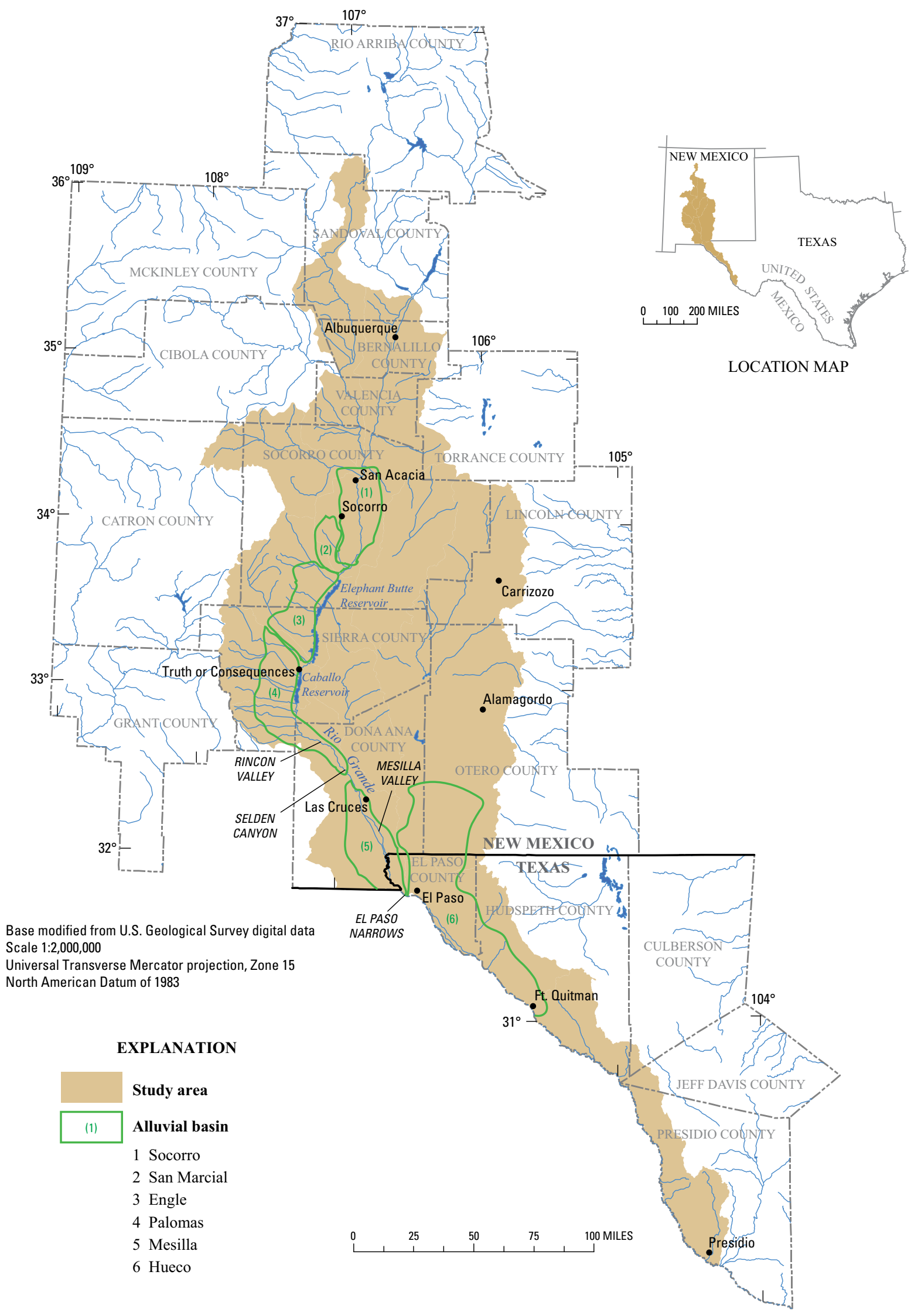

Figure 1. Spatial extent of existing data for the Rio Grande Basin, from the Rio Arriba-Sandoval County line, New Mexico, to Presidio, Texas, 2010. 


\section{Purpose and Scope}

The purpose of this report is to provide information on the design and compilation of a salinity geodatabase for the Rio Grande Basin from the Rio Arriba-Sandoval County line, N. Mex., to Presidio, Tex. Salinity-related data and ancillary information for more than 6,000 sampling sites were compiled from readily available sources in the study area. Following a brief description of the study area, the characteristics and function of the geodatabase are described, the methodology used to compile the water-quality components of the geodatabase is presented, and adiscussion of the compiled data is provided. The geodatabase is intended to provide detailed information regarding the primary sampling locations (referred to as sites) and the associated salinity data.

\section{Description of the Study Area}

Geospatial data were compiled for the part of the Rio Grande Basin extending from the Rio Arriba-Sandoval County line, N. Mex., to Presidio, Tex. In addition to compiling readily available surface-water-quality data, groundwater data were compiled for selected shallow alluvial and basin-fill aquifers located within the Rio Grande Rift Basin along an approximately 300-mile reach of the Rio Grande in the study area, from about 5 miles north of San Acacia, N. Mex., to about 6 miles south of Fort Quitman, Tex. (fig. 1).

The Rio Grande overlies six alluvial-fill basins in the study area-Socorro, San Marcial, Engle, Palomas, Mesilla, and Hueco (Wilkins, 1998). Detailed descriptions of the geologic structure of the alluvial-fill basins are given in Chapin (1971), Hawley (1978), Riecker (1979), Hawley and Kennedy (2004), Hawley and others (2005), and Hutchison (2006).

In the study area, the Rio Grande is generally a gaining stream; groundwater inflow contributes to streamflow throughout Rincon and Mesilla Valleys. The Rio Grande is the ultimate point of discharge for the regional flow system which includes both the shallow alluvial aquifer of Rincon and Mesilla Valleys and the deeper regional flow system (Wilson and others, 1981; Bexfield and Anderholm, 1997; Hibbs and others, 2003). However, during periods of drought, some reaches become losing streams (Wilson and others, 1981; Nickerson, 1995; Anderholm, 2002) when increased groundwater pumping causes drawdown and reversed gradients (Conover, 1954; Frenzel and others, 1992).

According to Phillips and others (2003), salinity concentrations are highest during the winter low-flow period when the majority of the observed flow in the Rio Grande consists of groundwater and municipal discharge. Low-flow conditions with high concentrations of salinity-related constituents limit the use of Rio Grande water for municipal supply and adversely affect agricultural and environmental uses. Phillips and others (2003) reported that salinity increased in a series of distinct "steps" from about 40 to about 2,000 milligrams per liter $(\mathrm{mg} / \mathrm{L})$ in a 1,200-kilometer stretch of the Rio Grande between its headwaters in southern Colorado and the United
States-Mexico border region; some distinct steps of large increases in salinity were measured at San Acacia, N. Mex., Selden Canyon upstream from Las Cruces, N. Mex., and El Paso Narrows upstream from El Paso, Tex. (fig. 1).

\section{Methodology}

A geodatabase is a spatially enabled database that contains spatial and non-spatial information; it is an extension of tabular data that allows users to correlate data with physical and spatial components. With a geodatabase, geographically referenced data can be manipulated using a geographic information system (GIS) to produce maps, interactive queries, and various types of spatial analyses. A geodatabase provides a framework and an interactive tool to aid in understanding spatial trends in water-quality analysis. The various types of data are separated into relational tables in the geodatabase on the basis of how they interact and correspond with the spatial feature class. The relational tables represent a collection of features and the relations between them.

The geodatabase was built using ESRI ArcGIS and Microsoft $\odot$ Access software. Multiple agencies and universities (listed in the "Introduction" section) maintain salinityrelated data that were used to construct the geodatabase in that part of the Rio Grande Basin defined by the study area. The primary steps involved in developing the geospatial database were compiling data, entering data into the geodatabase, ensuring data quality, and documenting the associated metadata.

\section{Geodatabase Design}

The geodatabase was designed to be a single, comprehensive repository for salinity-related data and ancillary information for the study area maintained by numerous Federal, State, and local agencies and universities. Wellborn and Moreo (2007, p. 4) describes the elements of an efficient geodatabase design, elements used in the design of this geodatabase: "a thematic approach [is used] to create layers of feature data within a geographic information system (GIS). The various features are stored as relational tables in the geodatabase on the basis of how the features interact and correspond to one another. These features, tables, and relations represent realworld spatial, temporal, and descriptive attribute interactions (Zeiler, 1999)."

For this geodatabase, point feature classes represent sampling locations in the study area. Attribute information tables are used to store detailed information needed to link information from related tables of data. The geodatabase contains one point feature class, five attribute information tables, and two relationship classes (table 1). The feature class stores the spatial location of primary sampling sites. The information tables store records linked to the feature class and include the site table, sample table, result table, 
Table 1. Description and definition of data compiled and entered into the geodatabase of water-quality information for the Rio Grande Basin, from the Rio Arriba-Sandoval County line, New Mexico, to Presidio, Texas, 2010.

[id, identifier]

\begin{tabular}{|c|c|c|}
\hline $\begin{array}{l}\text { Feature class } \\
\text { or table name }\end{array}$ & Data type & Definition \\
\hline site & Point feature class & $\begin{array}{l}\text { Spatial locations of sampling sites. Attributes include site id, site description, type code } \\
\text { original, latitude, longitude, horizontal datum, altitude, vertical datum, site source, } \\
\text { comments, subtype code, and site alias. }\end{array}$ \\
\hline sample & Attribute information table & $\begin{array}{l}\text { Non-spatial site information from collecting agencies. Attributes include site id, date/ } \\
\text { time, top of sample, bottom of sample, aquifer code, and collecting agency. }\end{array}$ \\
\hline param_code & Attribute information table & $\begin{array}{l}\text { Non-spatial site information compiled from reported data. Used as a domain to describe } \\
\text { the parameter code stored in the result table. Attributes include parameter code, } \\
\text { description, common name, and parameter group. }\end{array}$ \\
\hline data_source & Attribute information table & $\begin{array}{l}\text { Non-spatial data source information. Used as a domain to describe the data source } \\
\text { and provide metadata in the result table. Attributes include data source code and } \\
\text { description. }\end{array}$ \\
\hline site_sample & Relationship class & $\begin{array}{l}\text { Connection between the primary site feature class and the site information table. } \\
\text { Allows duplicate representations of a single site to be connected for display and } \\
\text { analysis. The site id field in the primary site feature class is linked to the primary site } \\
\text { id field in the sample information table. }\end{array}$ \\
\hline sample_result & Relationship class & $\begin{array}{l}\text { Connection between the sample information table and the result table. The sample } \\
\text { id field in the sample information table is linked to the sample id field in the result } \\
\text { information table. }\end{array}$ \\
\hline
\end{tabular}

param_codes (parameter list) table (hereinafter, parameter refers to water-quality physical properties and constituents), collecting-agency table, and data-source table (fig. 2, table 1). To connect data from the information tables to the geographic features contained in the feature class, relationship classes are created that use identical, unique identifiers in each data type to establish a relation between records in the geodatabase. The site table contains all site information compiled during sample collection as well as a primary site identification code so site locations that are common among the reporting agencies are coded to a single feature. The result table contains salinityrelated water-quality data and documents the reporting data source at the results level. The parameter list table contains descriptions of all water-quality parameters, unique parameter codes, commonly used parameter names, and parameter groups. A parameter stored in the result table is automatically interpreted using a domain (Zeiler, 1999) based on the parameter list table, so that the parameter description is visible in tables and in spatial queries when viewed in ArcGIS. A domain definition includes the precise description of the set of values (objects) constituting the domain (McLeod, 1976). The use of a parameter code rather than the full parameter description in the result table increases storage, retrieval, and updating efficiency. The collecting-agency table and data-source table contain non-spatial data that provide detailed information about the agencies and universities that collected and provided the data. This information is also used as domains and provides record-level metadata in the result and sample tables.

\section{Geodatabase Compilation}

As a first step, environmental data were compiled from existing digital databases maintained by Federal, State, and local agencies and universities (table 2). The USGS, USEPA, NMISC, and SAHRA maintain extensive environmental databases that include salinity-related water-quality data; these databases provided the majority of the data compiled. USGS water-quality data were obtained from the National Water Information System (NWIS). USGS data include 


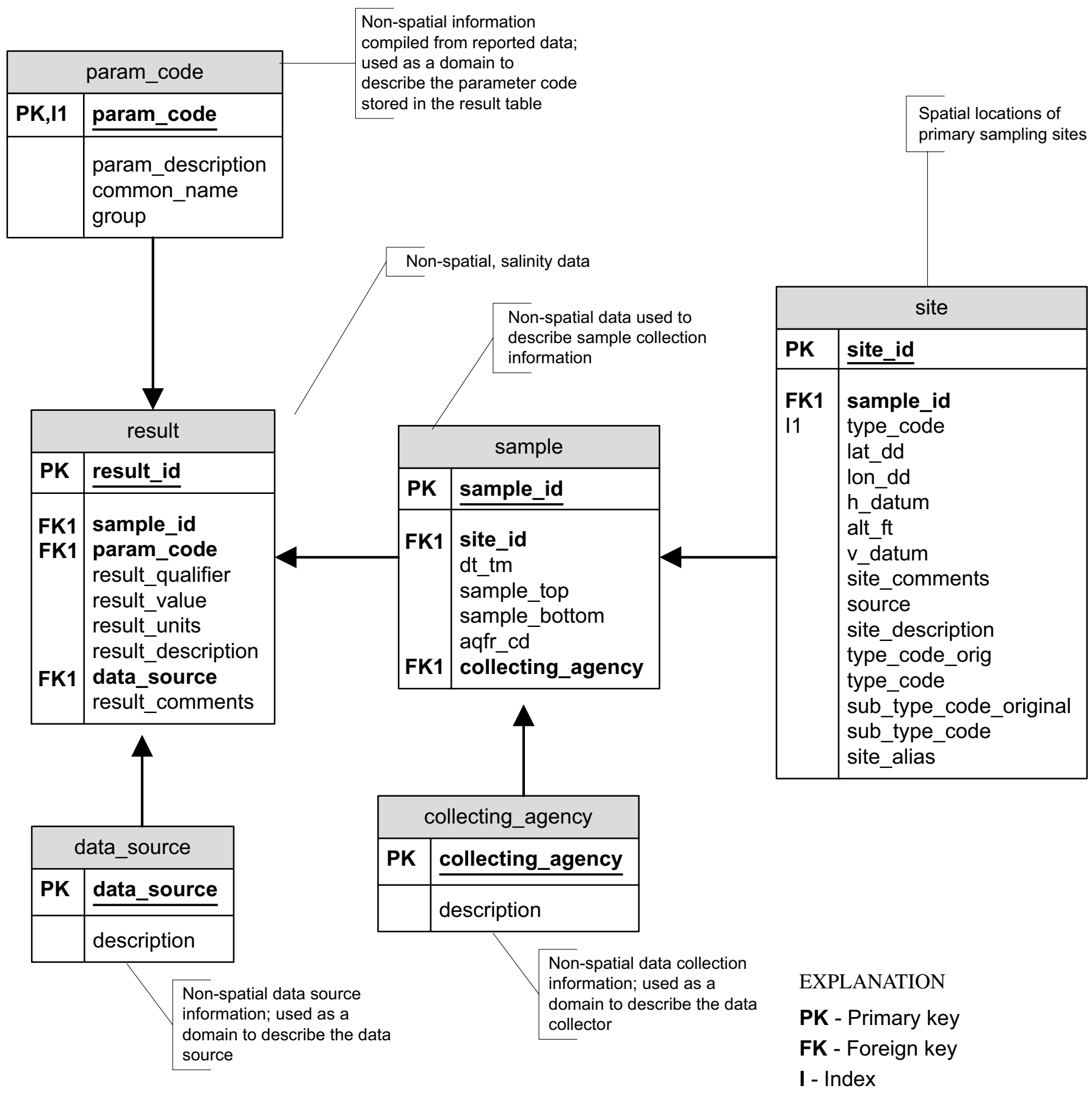

Figure 2. Diagram showing relational tables in the geodatabase of water-quality information for the Rio Grande Basin, from the Rio Arriba-Sandoval County line, New Mexico, to Presidio, Texas, 2010.

water-quality measurements taken as part of routine sampling and project-specific sampling in the New Mexico and Texas Water Science Centers (U.S. Geological Survey, 2009). USEPA data were obtained from the Modernized and Legacy Storage and Retrieval Repository (STORET) and include data supplied by State and local agencies (U.S. Environmental Protection Agency, 2009). NMISC data were obtained from and compiled by S.S. Papadopulos and Associates (written commun., 2003) from masters' theses, historical database compilations, reports compiled by the New Mexico Office of the State Engineer, and data downloaded from USEPA and USGS. SAHRA data were obtained as a database and include routine sampling data. Additional data sources (appendix 1) were included in the final database and are listed in table 2. Data compilation notes are listed in appen$\operatorname{dix} 2$. 
Table 2. Sources of data compiled and entered into the geodatabase of water-quality information for the Rio Grande Basin, from the Rio Arriba-Sandoval County line, New Mexico, to Presidio, Texas.

\section{Supplying entity or report}

Sample count Sample years

\section{U.S. Geological Survey (USGS), National Water Information System}

New Mexico Water Science Center

Texas Water Science Center

$1,321 \quad 1970$ to 2008

U.S. Environmental Protection Agency (EPA), Modernized and Legacy Storage and Retrieval Repository (STORET)

EPA STORET Modern data download

EPA STORET Legacy data download

New Mexico Interstate Stream Commission (NMISC), S.S. Papadopulos and Associates (SSPA) (written commun., 2003)

Data compilation for Rio Grande Project Conveyance System 1996 (Boyle Engineering Corp./

Parsons Engineering Science, Inc., written commun., 2009)

State Engineers Office 1986 database; CEP - EPEC

State Engineers Office 1986 database; CEP - LNE - TX

State Engineers Office 1986 database; City of El Paso, El Paso Water Utilities

State Engineers Office 1986 database; CEP, EPTL

State Engineers Office 1986 database; CEP, USGS

State Engineers Office 1986 database; City of El Paso

State Engineers Office 1986 database; El Paso Water Utilities

State Engineers Office 1986 database; CEP-CURTIS

State Engineers Office 1986 database; CEP-US ARMY

State Engineers Office 1986 database; EP CHEM-TEC

Lower Rio Grande (LRG) compendium (12/2008)

Data compilation for Rio Grande Project Conveyance System 1996 (Boyle Engineering Corp./

Parsons Engineering Science, Inc., written commun., 2009)

U.S. Geological Survey and Lower Rio Grande (USGS/LRG)

New Mexico Environment Department (NMED)

New Mexico Interstate Stream Commission (NMISC) Lower Rio Grande (LRG) Quarterly Monitoring

New Mexico State University, M.S. Thesis, Jerry H. Williams

"Salt Balance in the Rio Grande Project from San Marcial, New Mexico to Fort Quitman, Texas" (Williams, 2001)

\section{University of Arizona, Department of Hydrology and Water Resources}

Sustainability of semi-Arid Hydrology and Riparian Areas (SAHRA) database (http://www.sahra. arizona.edu/)

\section{New Mexico Environment Department (NMED)}

New Mexico Environment Department (NMED) and New Mexico Interstate Stream Commission (NMISC) Lower Rio Grande (LRG) Quarterly Monitoring

\section{Wilson, Orr, White, and Roybal}

"Water Resources of the Rincon and Mesilla Valleys and adjacent areas, New Mexico" (Wilson and others, 1981)

\section{Texas Commission on Environmental Quality (TCEQ)}

TCEQ data download (http://www.tceq.state.tx.us/cgi-bin/compliance/monops/water_daily_ summary.pl?cams=719)

\section{Texas Water Development Board (TWDB)}

TWDB data download (http://www.twdb.state.tx.us/ publications/reports/GroundWaterReports/ GWDatabaseReports/GWdatabaserpt.htm)

Daniel B. Stephens and Associates, Inc. (DBSA) 
The next step after the environmental data were compiled was to identify and isolate salinity-specific data from the rest of the data received. A representative from the USGS, New Mexico Water Science Center (Doug Moyer) was consulted to develop a list of potential terms that might have been used to describe salinity-related constituents (referred to as parameters in this geodatabase) as part of a salinity-related water-quality investigation. A search of all parameters used in each agency or university database was done and the resulting salinityspecific data were then reviewed by NMISC and USACE. A table of all parameters used to describe results reported by source agencies was generated and used for data querying and quality-assurance measures.

\section{Data Input}

Comparable fields within each agency's data structure were identified. Structured query language (SQL) code automated the creation of tables for site, sample, parameter, and result data (appendixes 3 and 4). The SQL code isolates appropriate data, then maps comparable fields and appends them into a single table. Once the tables were created, they were loaded into a geodatabase framework that supports linked tables, domains to interpret coded values, and spatial locations. This automation documents the comparable fields, selects appropriate data, and facilitates updates to minimize human error.

\section{Data Quality Assurance}

Duplicate data can occur when multiple agencies are reporting the same data in one or more databases used in a compilation effort. Elimination of duplicate data is essential to ensure the integrity of data being queried and ensures that the database does not contain information that could bias subsequent analyses.

Identification of duplicate data was performed both spatially (location on the earth) and temporally (date and time). Database queries analyzed site name and sample dates whereas spatial analysis compared site locations. Sample information queries were written to identify potential duplicate data on the basis of location and date. Samples were considered duplicates if the site identifier, sample date, and parameter result values were identical. If an entire dataset was duplicated elsewhere, the original dataset was used and the duplicate excluded.

To examine duplicates based on proximity or spatial location, all sites within 30 meters of another site were visually inspected using ESRI ArcGIS ${ }^{\text {TM }}$ software. If a site was within the 30-meter buffer or very close to a USGS site (well or gage), then the USGS site location was given priority and input into the geodatabase. If no USGS site locations were found within the 30-meter buffer, then criteria based on originating agency, site period of record, and data richness of the site location were used to establish the site identifier, which was captured in the geodatabase. Additional methods such as examining well locations with digital orthophoto quarter quadrangles and USGS topographic maps were used to determine the accuracy of the spatial coordinates assigned by an agency or individual.

\section{Metadata}

Metadata that comply with Federal Geographic Data Committee (FGDC) standards were created for each spatial component. The metadata record documents the basic characteristics of the data or information resource in the study area. Metadata components include information such as the title, abstract, and publication date of source documents; geographic elements such as geographic extent and projection information; and database elements such as attribute label definitions and attribute domain values. The metadata record for the sites feature class is contained in appendix 5.

\section{References}

Allison, G.B., Cook, P.G., Barnett, S.R., Walker, G.R., Jolly, I.D., and Hughes, M.W., 1990, Land clearance and river salinization in the western Murray Basin, Australia: Journal of Hydrology, v. 119, p. 1-20.

Anderholm, S.K., 2002, Water-quality assessment of the Rio Grande Valley, Colorado, New Mexico, and TexasSurface-water quality, shallow ground-water quality, and factors affecting water quality in the Rincon Valley, southcentral New Mexico, 1994-95: U.S. Geological Survey Water-Resources Investigations Report 02-4188, 117 p.

Benke, A.C., and Cushing, C.E., eds., 2005, Rivers of North America: Academic Press, 1,144 p.

Bexfield, L.M., and Anderholm, S.K., 1997, Water-quality assessment of the Rio Grande Valley, Colorado, New Mexico, and Texas-Ground-water quality in the Rio Grande flood plain, Cochiti Lake, New Mexico, to El Paso, Texas, 1995: U.S. Geological Survey Water-Resources Investigations Report 96-4249, 93 p.

Chapin, C.E., 1971, The Rio Grande Rift, part 1-Modifications and additions, in James, H.L., ed., Guidebook of the San Luis Basin, Colorado: New Mexico Geological Society, Twenty-Second Field Conference, p. 191-201.

Conover, C.S., 1954, Ground-water conditions in the Rincon and Mesilla Valleys and adjacent areas in New Mexico: U.S. Geological Survey Water-Supply Paper 1230, 200 p.

Frenzel, P.F., Kaehler, C.A., and Anderholm, S.K., 1992, Geohydrology and simulation of ground-water flow in the Mesilla Basin, Doña Ana County, New Mexico, and El Paso 
County, Texas: U.S. Geological Survey Professional Paper 1407-C, 105 p.

Hawley, J.W., 1978, Guidebook to the Rio Grande Rift in New Mexico and Colorado: New Mexico Bureau of Mines and Mineral Resources Circular 163, 241 p.

Hawley, J.W., and Kennedy, J.F., 2004, Creation of a digital hydrogeologic framework model of the Mesilla Basin and southern Jornada del Muerto Basin: Las Cruces, N. Mex., New Mexico Water Resources Research Institute of New Mexico State University, Technical Completion Report 332, $105 \mathrm{p}$.

Hawley, J.W., Kennedy, J.F., Ortiz, Marquita, and Carrasco, Sean, 2005, Digital hydrogeologic framework model of the Rincon Valley and adjacent areas of Doña Ana, Sierra and Luna Counties, NM: Las Cruces, N. Mex., New Mexico Water Resources Research Institute of New Mexico State University, addendum to Technical Completion Report 332, accessed October 22, 2009, at http://wrri.nmsu.edu/publish/ techrpt/tr332/cdrom/addendum.pdf.

Hibbs, Barry, Phillips, Fred, Hogan, James, Eastoe, Chris, Hawley, John, Granados, Alfred, and Hutchison, Bill, 2003, Hydrogeologic and isotopic study of the groundwater resources of the Hueco Bolson aquifer, El Paso, Texas/ Juarez, Mexico area: Hydrological Science and Technology, v. 19 , no. $1-4$, p. $109-119$.

Hutchison, W.R., 2006, Groundwater management in El Paso, Texas: University of Texas at El Paso, Ph.D. dissertation, 329 p.

Langman, J.B., 2009, Traveltime of the Rio Grande in the Middle Rio Grande Basin, water years 2003-05: U.S. Geological Survey Scientific Investigations Report 2007-5292, $34 \mathrm{p}$.

McLeod, D.J., 1976, High level domain definition in a relational data base system, in Conference on Data-Abstraction, Definition and Structure, Proceedings: Association for Computing Machinery Portal, v. 8, no. 2, p. 45-57.

Mills, S.K., 2003, Quantifying salinization of the Rio Grande using environmental tracers: Socorro, N. Mex., New Mexico Institute of Mining and Technology, M.S. thesis, 397 p., available at http://dspace.nmt.edu/dspace/handle/10136/437 ?mode $=$ full \&submit_simple $=$ Show + full + item + record .

Moore, S.J., and Anderholm, S.K., 2002, Spatial and temporal variations in streamflow, dissolved solids, nutrients, and suspended sediment in the Rio Grande Valley study unit, Colorado, New Mexico, and Texas, 1993-95: U.S. Geological Survey Water-Resources Investigations Report 02-4224, $52 \mathrm{p}$.
Nickerson, E.L., 1995, Selected hydrologic data for the Mesilla ground-water basin, 1987 through 1992 water years, Doña Ana County, New Mexico, and El Paso County, Texas: U.S. Geological Survey Open-File Report 95-111, $123 \mathrm{p}$.

Phillips, F.M., Hogan, J.F., Mills, S.K., and Hendrickx, J.M.H., 2003, Environmental tracers applied to quantifying causes of salinity in arid-region rivers-Preliminary results from the Rio Grande, southwestern USA, in Alsharhan, A.S., and Wood, W.W., eds., Water resources perspectivesEvaluation, management, and policy: Amsterdam, Elsevier, Developments in Water Science, v. 50, p. 327-334.

Pillsbury, A.F., 1981, The salinity of rivers: Scientific American, v. 245 , no. 1 , p. 54-65.

Riecker, R.R., ed., 1979, Rio Grande Rift-Tectonics and magmatism: American Geophysical Union, 438 p.

Stabler, Herman, 1911, Some stream waters of the western United States, with chapters on Sediment carried by the Rio Grande and the industrial application of water analyses: U.S. Geological Survey Water-Supply Paper 274, 188 p.

U.S. Environmental Protection Agency, 2009, Modernized Storage and Retrieval repository: accessed January 5, 2009, at http://www.epa.gov/storet/about.html.

U.S. Geological Survey, 2009, National Water Information System (NWIS Web): accessed January 4, 2009, at http:// waterdata.usgs.gov/nwis.

Wellborn, T.L., and Moreo, M.T., 2007, Irrigated acreage within the Basin and Range carbonate-rock aquifer system, White Pine County, Nevada, and adjacent areas in Nevada and Utah: U.S. Geological Survey Data Series 273, 17 p., accessed online January 21, 2010, at http://pubs.usgs.gov/ $d s / 2007 / 273 / p d f / d s 273 . p d f$.

Wilkins, D.W., 1998, Summary of the southwest alluvial basins regional aquifer-system analysis in parts of Colorado, New Mexico, and Texas: U.S. Geological Survey Professional Paper 1407-A, 49 p.

Williams, J.H., 2001, Salt balance in the Rio Grande project from San Marcial, New Mexico to Fort Quitman, Texas: Master's thesis, New Mexico State University, 80 p.

Wilson, C.A., White, R.R., Orr, B.R., and Roybal, G.R., 1981, Water resources of the Rincon and Mesilla Valleys and adjacent areas, New Mexico: New Mexico State Engineer Technical Report 43, 514 p.

Zeiler, Michael, 1999, Modeling our world-The ESRI guide to geodatabase design: Redlands, Calif., ESRI Press, $216 \mathrm{p}$. 
Appendixes 
Blank Page 


\section{Abbreviations}

DBSA, Daniel B. Stephens and Associates, Inc.

EPA, U.S. Environmental Protection Agency

FGDC, Federal Geographic Data Committee

$I D$, identifier

LRG, Lower Rio Grande

NMED, New Mexico Environmental Department

NWIS, National Water Information System

SAHRA, Sustainability of semi-Arid Hydrology and Riparian Areas

SSPA, S.S. Papadopulos and Associates

STORET, Storage and Retrieval Repository

TCEQ, Texas Commission on Environmental Quality

TWDB, Texas Water Development Board

USGS, U.S. Geological Survey

WILSON, Wilson and others (1981) 


\section{Appendix 1-Data Sources}

\section{USGS-New Mexico}

Source: Internal data access direct from NWIS.

Processing: Created unique parameters and sample IDs by prefixing with 'USGSNM'.

Date Range: 1/1/1901-7/28/2009

\section{USGS-Texas}

Source: Internal data access direct from NWIS.

Processing: Created unique parameters and sample IDs by prefixing with 'USGSTX'.

Date Range: 1/1/1901-7/28/2009

\section{SAHRA}

Source: SAHRA Data

Processing: Created sample table. Prefixed parameters and sample IDs with 'SAHRA'. Data from Mills (2003) included.

Date Range: 1/28/2000-8/10/2006

\section{EPA STORET Modern}

Source: EPA Storet Modern

Processing: Created sample table. Filtered out data collected by 21TXWQB (Texas Water Commission, now TCEQ). Created unique parameters and sample IDs by prefixing with 'EPA'.

Date Range: $10 / 11 / 1937-5 / 3 / 2029 *$

\section{EPA STORET Legacy}

Source: EPA Storet Legacy

Processing: Created sample table. Filtered out data collected by 21TXWQB (Texas Water Commission, now TCEQ). Created unique parameters and sample IDs by prefixing with 'EPAL'.

Date Range: $10 / 11 / 1937-5 / 3 / 2029 *$

\section{TCEO}

Source: Texas Commission on Environmental Quality

Processing: Imported data by basin (Rio Grande, Rio Grande-Nueces) for sites and results. Created sample table by site and sample date. Created unique parameters and sample IDs by prefixing with 'TCEQ'.

Date Range: 9/18/1968-8/26/1992

\section{TWDB}

Source: Texas Water Development Board

Processing: Downloaded geodatabase. Appended water-quality data in a new table, changing horizontal data to vertical. Filtered out USGS data. Created unique parameters and sample IDs by prefixing with 'TWDB'.

Date Range: $1 / 1 / 1800 *-9 / 15 / 2007$ 


\section{SSPA}

Source: v3 WaterQuality

Processing: Created unique parameters and sample IDs by prefixing with 'SSPA'.

Date Range: $2 / 11 / 1931-12 / 15 / 1995$

Wilson, Orr, White, and Roybal

Source: Wilson Data

Processing: Created unique parameters and sample IDs by prefixing with ' $W$ '.

Date Range: 4/22/1936-9/18/1977

\section{DBSA}

Source: DBSA Water Quality

Processing: Excluded all data except Williams (2001) data from Tetra Tech and Daniel B. Stephens and Associates, Inc. (written commun., 2005) data. Mills (2003) data are included in SAHRA database. Created unique parameters and sample IDs by prefixing with 'DBSA'.

Date Range: $1 / 15 / 1934-1 / 27 / 2005$

\section{NMED}

Source: NMED LRG Monitoring

Processing: Created unique parameters and sample IDs by prefixing with 'NMED'.

Date Range: 5/23/20057*-2/14/2008

* Date not reliable 


\section{Appendix 2-Database Compilation Notes}

\section{Data Preparation}

To compile data from disparate sources, it is necessary to analyze, prepare, and standardize the data to create a comprehensive dataset. Data preparation included:

Identifying key data sources

Creating list of unique water-quality parameters

Creating table of unique samples

Analyzing data for duplicate records

Determining site locations (latitude and longitude)

Resolving duplicate sites

Once data were processed, UNION queries for site, sample, result, and parameter values put the data together in four tables.

\section{Duplicate Resolution}

\section{Samples and Results}

Sample and result data were imported into the salinity staging database and cross-checked for duplicates by sample date/time and parameter results. If a sample and result pair was duplicated in another dataset, the data closest to the original (native) data source was used. Example: USGS staff sampled a well on July 9, 2007, and uploaded results into NWIS. TWDB received the sample and result data and uploaded the results into their system. Because both systems contain the same information, the original data would be used, in this case NWIS.

\section{Example SQL Query for Locating Duplicate Samples}

SELECT Sample.site_id, Sample.dt_tm, Sample.collecting_agency, Sample.sample_id FROM Sample WHERE (((Sample. site_id) IN (SELECT [site_id] FROM [Sample] AS Tmp GROUP BY [site_id],[dt_tm] HAVING Count $(*)>1$ AND [dt_tm] = [Sample].[dt_tm])) ORDER BY Sample.site_id, Sample.dt_tm;

\section{Sites}

The following process was used to determine duplicate sites:

Remove duplicate sites with same name, longitude, and latitude (use original data)

Create 30-meter buffer around all sites

Consider duplicates to be within the overlap of buffers

All sites that are duplicates of USGS sites were flagged with USGS site name as primary site

All sites within the buffer and with different names were left in the database

\section{Example SQL Query for Locating Duplicate Sites}

SELECT Sites.site_id, Count(Sites.site_id) AS CountOfsite_id FROM Sites GROUP BY Sites.site_id HAVING $((($ Count $($ Sites.site_id $))>1))$; 


\section{Appendix 3-Union Queries}

A union query combines the result sets of several similar select queries. For example, suppose that you have one table that stores information about customers, another table that stores information about suppliers, and no relation exists between the two tables. Suppose that both tables have fields that store contact information, and you want to look at all of the contact information from both tables at the same time. You could create a select query (select query: A query that asks a question about the data stored in your tables and returns a result set in the form of a datasheet, without changing the data) for each table to retrieve only those fields that contain contact information, but the information that is returned would still be in two separate places. To combine the results of two or more select queries into one result set, you can use a union query.

\section{SOL Code for Site Union Query}

SELECT s.site_no as site_id, s.site_tp_cd AS type_code, s.dec_lat_va AS lat_dd, s.dec_long_va AS lon_dd, s.coord_datum_cd $\mathbf{A S}$ h_datum, s.alt_va AS alt_ft, s.alt_datum_cd AS v_datum, "" AS site_comments, "NWIS NM" AS source

FROM [datalUSGS_NMlupdate_20090819\nwisdb_gdb_01.mdb].sitefile AS s

UNION

SELECT s.site_no as site_id, s.site_tp_cd AS type_code, s.dec_lat_va AS lat_dd, s.dec_long_va AS lon_dd, s.coord_datum_cd AS h_datum, s.alt_va AS alt_ft, s.alt_datum_cd AS v_datum, "" AS site_comments, "NWIS TX" AS source

FROM [datalUSGS_TXlupdate_20090819\nwisdb_gdb_01.mdb].sitefile AS s

UNION

SELECT s.[SiteCode] AS site_id, "SW" AS type_code, s.[Latitude] AS lat_dd, s.[Longitude] AS lon_dd, "' AS h_datum, s.[Elevation_m] AS alt_ft, s.[VerticalDatum] AS v_datum, "" AS site_comments, "SAHRA" AS source

FROM [datalSAHRA_20081210/RioGrandeWQ_ODM_working_v3_NoMisVal.mdb].Sites AS s

UNION

SELECT s.Site_ID, s.[site_type] AS type_code, s.[Latitude] AS lat_dd, s.[Longitude] AS lon_dd, s.[Datum] AS h_datum, 0 AS alt_ft, "" AS v_datum, "" AS site_comments, "STORET MODERN" AS source

FROM [datalEPA\Modernized $20090728 \backslash$ EPAModern.mdb].Sites AS s

UNION

SELECT s.site_id, s.[TYPE] AS type_code, s.lat_dd, s.lon_dd, s.h_datum_dd, s.alt_ft, s.v_datum, "" AS site_comments, "STORET LEGACY" AS source

FROM [datalEPAlLegacylEPA_Legacy2.mdb].TBL_LOC AS s

UNION

SELECT s.[Station_ID] AS site_id, s.[Stream_Station_Type_1] AS type_code, s.Latitude, s.Longitude, "' AS h_datum, "" AS alt_ft, "" AS v_datum, "" AS site_comments, "TCEQ" AS source

FROM [datalTCEQITCEQ.mdb].TCEQ_Stations AS s

UNION

SELECT w.[state_well_number] AS site_id, "WELL" AS type_code, w.[lat_dec] AS lat_dd, w.[long_dec] AS lon_dd, "" AS h_datum, "" AS alt_ft, "" AS v_datum, "" AS site_comments, "TWDB" AS source

FROM [datalTWDB\TWDB.mdb].mASter_sample AS s INNER JOIN [datalTWDB\TWDB.mdb].welldata AS w ON s.state_ well_number $=$ w.state_well_number WHERE $((($ w.county_code $)=141$ Or $($ w.county_code $)=229$ Or $($ w.county_code $)=377))$ UNION

SELECT c.[Site ID] AS site_id, s.[Water Type Code] AS type_code, c.[LAT (DD)] AS lat_dd, c.[LONG (DD)] AS lon_dd, c.[DD Datum] AS h_datum, c.[ALTITUDE (FT)] AS alt_ft, c.[ALT Datum] AS v_datum, "" AS site_comments, "SSPA" AS source

FROM [datalSSPA_V2_2004_Data_compendium|WaterQualitylv3WaterQuality.mdb].[TBL WQ Site Info] AS s INNER JOIN [datalSSPA_V2_2004_Data_compendium|WaterQualitylv3WaterQuality.mdb].v2_SiteID_CoordinateData AS c ON s.[Site ID]

$=\mathrm{c}$. [Site ID]

UNION

SELECT 1.Site_ID, "" AS type_code, 1.[Latitude] AS lat_dd, 1.[Longitude] AS lon_dd, "NAD83" AS h_datum, 1.[GE] AS alt_ft, "" AS v_datum, "" AS site_comments, "WILSON Calc" AS source

FROM [datalWilsonlWilsonData.mdb].WilsonWells AS 1

UNION

SELECT 1.[Site ID] AS Loc_id, s.[Water Type Code] AS type_code, 1.[Latitude DD] AS lat_dd, 1.[Longitude DD] AS lon_dd, 1.[Horiz Datum DD] AS h_datum, 1.[Elevation (ft)] AS alt_ft, 1.[Vert Datum] AS v_datum, "" AS site_comments, "DBSA" AS source 
FROM [datalNMISC_20081120\SurfaceWater|Sources\DBSAIDBSAWaterQuality.mdb].[TBL WQ Location] AS 1 INNER JOIN [datalNMISC_200811201SurfaceWater|Sources\DBSAIDBSAWaterQuality.mdb].[TBL_Sample] AS s ON 1.[Site ID] = s.[Site ID]

UNION

SELECT 1.Site_ID, 1.[Type] AS type_code, 1.[Latitude] AS lat_dd, 1.[Longitude] AS lon_dd, 1.[HorizontalDatum] AS h_datum, 1.[Elevation] AS alt_ft, 1.[VerticalDatum] AS v_datum, "" AS site_comments, "NMED" AS source

FROM [datalNMISC_Compendium_20090624lCompendium_1208ISurfaceWater|SourceslNMEDINMED_LRG_Monitoring_1208.mdb].TBL_LOC AS 1;

\section{SOL Code for Sample Union Query}

SELECT 'USGSNM' \& s.[record_no] AS sample_id, s.site_no AS site_id, s.sample_start_dt AS dt_tm, 0 AS sample_top, 0 AS sample_bottom, s.aqfr_cd, "USGS_" \& s.coll_ent_cd AS collecting_agency FROM [datalUSGS_NMlupdate_20090819 nwisdb_gdb_01.mdb].qw_sample AS s

\section{UNION}

SELECT 'USGSTX' \& s.[record_no] AS sample_id, s.site_no AS site_id, s.sample_start_dt AS dt_tm, 0 AS sample_top, 0 AS sample_bottom, s.aqfr_cd, "USGS_" \& s.coll_ent_cd AS collecting_agency

FROM [datalUSGS_TXlupdate_20090819 nnwisdb_gdb_01.mdb].qw_sample AS s

UNION

SELECT s.sample_id, s.site_ID, s.dt_tm, s.Sample_top, s.Sample_bottom, "" AS aqfr_cd, "SAHRA" AS collecting_agency

FROM [datalSAHRA_20081210\RioGrandeWQ_ODM_working_v3_NoMisVal.mdb].Sample2 AS s

UNION

SELECT s.sample_id, s.Site_ID, s.dt_tm, s.Sample_Top, s.Sample_Bottom, s.aqfr_cd, "EPA_" \& s.collecting_agency

FROM [datalEPA \Modernized\20090728\EPAModern.mdb].Samples AS s

UNION

SELECT s.sample_id, s.Site_ID, s.dt_tm, s.Sample_Top, s.Sample_Bottom, s.aqfr_cd, "EPA_" \& s.collecting_agency

FROM [datalEPA LegacylEPA_Legacy2.mdb].Sample AS s

UNION

SELECT "TCEQ" \& s.[Tag_ID] AS sample_id, s.Station_ID AS site_id, Format(s.[enddate] \& " " \& s.[endtime],"General Date") AS dt_tm, s.StartDepth AS sample_top, s.EndDepth AS smaple_bottom, "" AS aqfr_cd, "TCEQ_" \& s.CollectingEntity AS collecting_agency

FROM [datalTCEQITCEQ.mdb].Sample AS s

WHERE (((Sample.SubmittingEntity)<>"GS"))

UNION

SELECT "TWDB" \& s.[sample_idx] AS sample_id, s.state_well_number AS site_id, s.date_tm AS sample_dt, s.top_s_interval AS sample_top, s.bottom_s_interval AS sample_bottom, s.samp_int_aqcode AS aqfr_cd, "TWDB_" \& entity_codes.entity AS collecting_agency

FROM [datalTWDB\TWDB.mdb].master_sample AS s INNER JOIN [datalTWDB \TWDB.mdb].entity_codes ON s.collecting_agency $=$ entity_codes.entity_code

WHERE ((entity_codes.entity_code)<>"03")) AND ((welldata.county_code)=141 OR (welldata.county_code)=229 OR (welldata.county_code $)=377)$ )

UNION

SELECT s.sample_id, s.Site_ID, s.dt_tm AS sample_dt, s.Sample_Top, s.Sample_Bottom, "SSPA_" \& s.coll_agency AS collecting_agency, s.aqfr_cd

FROM [datalSSPA_V2_2004_Data_compendium|WaterQualitylv3WaterQuality.mdb].TBL_Sample AS s

WHERE $((($ s.coll_agency) In $(1,4,5,8,9,10,11,13,14,15,16,17,18,19,21,26)))$

UNION

SELECT s.Sample_ID, s.Site_ID, s.Sample_Dt, s.Sample_Top, s.Sample_Bottom, "WILSON" AS collecting_agency, w.GU AS aqfr_cd

FROM [datalWilson|WilsonData.mdb].WilsonWells AS w INNER JOIN [datalWilson|WilsonData.mdb].Wilson_Sample AS s ON w.Site_ID $=$ s.Site_ID

UNION

SELECT s.sample_id, s.Site_ID, s.sample_date AS sample_dt, s.Sample_Top, s.Sample_Bottom, "DBSA_" \& s.collecting agency, s.aqfr_cd

FROM [datalNMISC_20081120\SurfaceWater|Sources\DBSAIDBSAWaterQuality.mdb].TBL_Sample AS s 
WHERE (((s.collecting_agency) In $(30,32)))$

\section{UNION}

SELECT s.Sample_ID, s.SiteID AS site_id, s.dt_tm AS sample_dt, s.Sample_Top, s.Sample_Bottom, "NMED" AS Collecting_agency, "" AS aqfr_cd

FROM [datalNMISC_Compendium_20090624ICompendium_1208ISurfaceWater|SourcesINMEDINMED_LRG_Monitoring_1208.mdb].Sample AS s;

\section{SOL Code for Result Union Query}

SELECT "USGSNM" \& r.record_no AS sample_id, "USGS" \& r.parm_cd AS param_code, r.remark_cd AS result_qualifier, r.result_va AS result_value, p.units AS result_units, "" AS result_description, "USGS" AS distributing_agency, "" AS [result_ comments]

FROM tbl_search AS t INNER JOIN ([\Ugskiacwgsnaslgis_projlb8653_dp6ldatalUSGS_NMlupdate_20090819\nwisdb_ gdb_01.mdb].qw_sample AS s INNER JOIN ([IIIgskiacwgsnasłgis_projlb8653_dp6ldatalUSGS_NMlupdate_20090819 nwisdb_gdb_01.mdb].qw_result AS r INNER JOIN [MIgskiacwgsnaslgis_projlb8653_dp6ldatalUSGS_NMlupdate_20090819\ nwisdb_gdb_01.mdb].Pmcodes AS p ON r.parm_cd=p.parameter_cd) $\mathbf{O N}$ s.record_no=r.record_no) $\mathbf{O N}$ p.parameter_nm like t.Term WHERE (((s.sample_start_dt) Is Not Null))

UNION

SELECT "USGSTX" \& r.record_no AS sample_id, "USGS" \& r.parm_cd AS param_code, r.remark_cd AS result_qualifier, r.result_va AS result_value, p.units AS result_units, "" AS result_description, "USGS" AS distributing_agency, "" AS [result_ comments]

FROM tbl_search AS t INNER JOIN ([UIgskiacwgsnasłgis_projlb8653_dp6ldatalUSGS_TXlupdate_20090819lnwisdb_ gdb_01.mdb].qw_sample AS s INNER JOIN ([IIIgskiacwgsnaslgis_projlb8653_dp6ldatalUSGS_TXlupdate_20090819 nwisdb_gdb_01.mdb].qw_result AS r INNER JOIN [\Igskiacwgsnaslgis_projlb8653_dp6ldatalUSGS_TXlupdate_20090819 nwisdb_gdb_01.mdb].Pmcodes AS p ON r.parm_cd=p.parameter_cd) $\mathbf{O N}$ s.record_no=r.record_no) $\mathbf{O N}$ p.parameter_nm like t.Term WHERE (((s.sample_start_dt) Is Not Null))

\section{UNION}

SELECT sa.sample_id, "SAHRA" \& Format([v].[VariableID]) AS param_code, cv.symbol AS result_qualifier, dv.DataValue AS result_value, UCase([UnitsAbbreviation]) AS result_units, cv.Definition AS result_description, "SAHRA" AS distributing_agency, "" AS result_comments

FROM [MIgskiacwgsnas\gis_projlb8653_dp6ldatalSAHRA_20081210\RioGrandeWQ_ODM_working_v3_NoMisVal. mdb].Units INNER JOIN ([IUgskiacwgsnasłgis_projlb8653_dp6ldatalSAHRA_20081210\RioGrandeWQ_ODM_working_v3_NoMisVal.mdb].Sample2 AS sa INNER JOIN ([\Igskiacwgsnasłgis_projlb8653_dp6ldatalSAHRA_20081210\RioGrandeWQ_ODM_working_v3_NoMisVal.mdb].CensorCodeCV AS cv INNER JOIN ([\Ugskiacwgsnasłgis_projlb8653_dp6\ datalSAHRA_20081210\RioGrandeWQ_ODM_working_v3_NoMisVal.mdb].Variables AS v INNER JOIN [MIgskiacwgsnaslgis_projlb8653_dp6ldatalSAHRA_20081210\RioGrandeWQ_ODM_working_v3_NoMisVal.mdb].DataValues AS dv ON v.VariableID $=$ dv.VariableID) $\mathbf{O N}$ cv.Term $=$ dv.CensorCode) $\mathbf{O N}$ sa.sample_id $=$ dv.sample_id) ON Units.UnitsID = v.VariableUnitsID

\section{UNION}

SELECT r.Sample_ID, "EPA" \& r.PCODE AS param_code, r.result_qualifier, r.result_value, UCase(r.[result_units]) AS Expr1, r.result_description, "EPA" AS distributing_agency, "" AS result_comments

FROM [MIgskiacwgsnasłgis_projlb8653_dp6ldatalEPAlModernized120090728\EPAModern.mdb].PCODE AS p INNER JOIN [MIgskiacwgsnas\gis_projlb8653_dp6ldatalEPA\ModernizedI20090728\EPAModern.mdb].QW_Res AS r ON p.PCODE = r.PCODE

WHERE $(((p . S A L I N I T Y)=" Y "))$

UNION

SELECT r.sample_id, "EPA" \& r.Param AS param_code, r.R AS result_qualifier, r.Result_Value, UCase(rc.[Name]) AS result_ units, "" AS result_description, "EPA" AS distributing_agency, "" AS result_comments

FROM ([\Ugskiacwgsnas\gis_projlb8653_dp6ldatalEPAlLegacylEPA_Legacy2.mdb].Parameter AS p INNER JOIN [IIIgskiacwgsnaslgis_projlb8653_dp6ldatalEPAlLegacylEPA_Legacy2.mdb].Reporting_codes AS rc ON p.Reporting_Units = rc.Code) INNER JOIN [MIgskiacwgsnaslgis_projlb8653_dp6ldatalEPAlLegacylEPA_Legacy2.mdb].Results AS r ON p.Param = r.Param WHERE $((($ p.selected $)=" Y "))$

\section{UNION}

SELECT "TCEQ" \& [r].[Tag_ID] AS sample_id, "TCEQ" \& r.Parameter_Code AS param_code, r.GreaterThan_LessThan AS result_qualifier, r.ResValue AS result_value, p.[Units of Measurement] AS result_units, "VERIFIED: " \& r.[VerifyFlag] AS 
result_description, "TCEQ" AS distributing_agency, "" AS result_comments

FROM [IIgskiacwgsnaslgis_projlb8653_dp6ldatalTCEQ।TCEQ.mdb].Sw_parm AS p INNER JOIN [IIgskiacwgsnas/gis_ projlb8653_dp6ldatalTCEQ।TCEQ.mdb].Results AS r ON p.Parameter_Code = r.Parameter_Code

WHERE $((($ p.selected $)=" Y "))$

UNION

SELECT "TWDB" \& [r].[sample_idx] AS sample_id, r.parm_cd AS param_code, r.remark_cd AS result_qualifier, r.result_va AS result_value, sc.units_of_measure AS result_units, "" AS result_description, "TWDB" AS distributing_agency, "" AS result_ comments

FROM tbl_search INNER JOIN ([\Igskiacwgsnaslgis_projlb8653_dp6ldatalTWDB\TWDB.mdb].welldata INNER JOIN ([\\

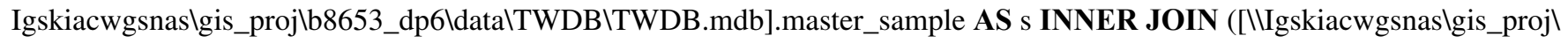

b8653_dp6\datalTWDB\TWDB.mdb].storet_code AS sc INNER JOIN [IIgskiacwgsnas \gis_projlb8653_dp6ldata|TWDB।

TWDB.mdb].master_result AS r ON sc.storet_code = r.parm_cd) $\mathbf{O N}$ s.sample_idx = r.sample_idx) ON welldata.state_well_ number $=$ s.state_well_number) ON sc.long_description LIKE tbl_search.Term

WHERE $((($ s.collecting_agency $)<>" 03 ")$ AND ((welldata.county_code) $=141$ OR (welldata.county_code)=229 OR (welldata.

county_code $)=377)$ )

UNION

SELECT p.sample_id, "SSPA" \& p.[Parameter Code] AS param_code, p.Qualifier AS result_qualifier, p.Value AS result_value, UCase([Unit]) AS result_units, c.CommentDescrip AS result_description, "SSPA" AS distributing_agency, "" AS result_comments

FROM tbl_search INNER JOIN ([IIIgskiacwgsnas\gis_projlb8653_dp6ldatalSSPA_V2_2004_Data_compendium|WaterQualitylv3WaterQuality.mdb].QRY_Sample AS s INNER JOIN ([\Igskiacwgsnaslgis_projlb8653_dp6ldatalSSPA_V2_2004_Data_ compendium।WaterQualitylv3WaterQuality.mdb].[REF WQ Comment Code] AS c INNER JOIN [MIgskiacwgsnas\gis_proj। b8653_dp6ldatalSSPA_V2_2004_Data_compendiumlWaterQualitylv3WaterQuality.mdb].[TBL WQ Parameter] AS p ON c. $[$ Comment Code] $=$ p. $[$ Comment Code] $)$ ON s.sample_id = p.sample_id) $\mathbf{O N}$ p.Parameter like tbl_search.Term UNION

SELECT r.Sample_ID, r.Param AS param_code, "" AS result_qualifier, r.Result AS result_value, r.Units AS result_units, "" AS result_description, "WILSON" AS distributing_agency, "" AS result_comments

FROM [MIgskiacwgsnas|gis_projlb8653_dp6ldatalWilson|WilsonData.mdb].Wilson_WQ_Results AS r

UNION

SELECT r.sample_id, "DBSA" \& r.[Parameter Code] AS param_code, r.Qualifier AS result_qualifier, r.Value AS result_value, UCase([Unit]) AS result_units, r.[Comment Code] AS result_description, "DBSA" AS distributing_agency, "' AS result_comments

FROM [MIIgskiacwgsnas\gis_projlb8653_dp6ldatalNMISC_20081120\SurfaceWater|Sources\DBSAIDBSAWaterQuality.mdb]. QRY_Sample AS s INNER JOIN [IIgskiacwgsnas\gis_projlb8653_dp6ldatalNMISC_20081120\SurfaceWater|Sources\DBSA| DBSAWaterQuality.mdb].[TBL WQ Parameter] AS r ON s.sample_id = r.sample_id UNION

SELECT r.Sample_ID, "NMED" \& r.Pcode AS param_code, r.Qualification AS result_qualifier, r.Value_AS Result_Value, UCase(r.[Units]) AS result_units, r.Comment AS result_description, "NMED" AS distributing_agency, "" AS result_comments FROM [IIgskiacwgsnas\gis_projlb8653_dp6\datalNMISC_Compendium_20090624\Compendium_1208\SurfaceWater\ SourcesINMEDINMED_LRG_Monitoring_1208.mdb].SW_GW_Results AS r;

\section{SOL Code for Parameter Union Query}

SELECT "USGS" \& Pmcodes.parameter_cd AS param_code, Pmcodes.parameter_nm AS param_description FROM [datalUSGS_TXInwisdb_gdb_01.mdb].tbl_search INNER JOIN [datalUSGS_TXInwisdb_gdb_01.mdb].Pmcodes ON Pmcodes.parameter_nm LIKE tbl_search.Term

UNION

SELECT "SAHRA" \& [VariableID] AS param_code, Variables.VariableName AS param_description

FROM [datalSAHRA_20081210\RioGrandeWQ_ODM_working_v3_NoMisVal.mdb].Variables UNION

SELECT "EPA" \& [PCODE] AS param_code, PCODE.Characteristic_Name AS param_description FROM [datalEPA \Modernizedl20090728\EPAModern.mdb].PCODE WHERE (((PCODE.SALINITY)="Y")) UNION

SELECT "EPA" \& [parameter_code] AS param_code, STORET_PRM.Parameter AS param_description FROM [datalEPAlLegacylEPA_Legacy2.mdb].STORET_PRM WHERE (((STORET_PRM.selected)="Y")) 


\section{UNION}

SELECT "TCEQ" \& [Parameter_Code] AS param_code, Sw_parm.[Parameter Description] AS param_description FROM [datalTCEQITCEQ.mdb].Sw_parm INNER JOIN [datalTCEQITCEQ.mdb].tbl_search ON Sw_parm.[Parameter Description] LIKE tbl_search.Term

UNION

SELECT "TWDB" \& TWDBstoret.storet_code AS param_code, TWDBstoret.long_description AS param_description FROM [datalTWDB\TWDB.mdb].tbl_search INNER JOIN [datalTWDB \TWDB.mdb].TWDBstoret ON TWDBstoret.long description LIKE tbl_search.Term

UNION

SELECT "SSPA" \& [REF WQ Parameter Code].[Parameter Code] AS param_code, [REF WQ Parameter Code].[ParameterDesc] AS param_description

FROM [datalSSPA_V2_2004_Data_compendium|WaterQualitylv3WaterQuality.mdb].tbl_search INNER JOIN [datalSSPA_ V2_2004_Data_compendium|WaterQualitylv3WaterQuality.mdb].[REF WQ Parameter Code] ON [REF WQ Parameter Code]. ParameterDesc LIKE tbl_search.Term

UNION

SELECT Wilson_USGS_Param.Param AS param_code, Wilson_USGS_Param.Description AS param_description

FROM [datalWilsonlWilsonData.mdb].Wilson_USGS_Param

UNION

SELECT "DBSA" \& [REF WQ Parameter Code].[Parameter Code] AS param_code, [REF WQ Parameter Code].ParameterDesc AS param_description

FROM [datalNMISC_20081120\SurfaceWater|Sources\DBSAIDBSAWaterQuality.mdb].tbl_search INNER JOIN [datal NMISC_20081120\SurfaceWater|Sources\DBSAIDBSAWaterQuality.mdb].[REF WQ Parameter Code] ON [REF WQ Parameter Code].ParameterDesc LIKE tbl_search.Term

UNION

SELECT "NMED" \& [PCODE] AS param_code, SW_Parameters.[Parameter] AS param_description

FROM [datalNMISC_Compendium_20090624ICompendium_1208ISurfaceWater|SourceslNMEDINMED_LRG_Monitoring_1208.mdb].SW_Parameters; 


\section{Appendix 4-Data Query Examples}

\section{Query Results by Parameter Example}

SELECT sites.site_id, sample.dt_tm, param_codes.common_Name, result.result_qualifier, result.result_value, result.result_ units FROM ((sites INNER JOIN sample ON sites.site_id = sample.site_id) INNER JOIN result ON sample.sample_id = result.sample_id) INNER JOIN param_codes ON result.param_code = param_codes.param_code WHERE $((($ param_codes . common_Name)=[Enter Parameter to Search]));

\section{Query Results by Site Example}

SELECT sites.site_id, sample.dt_tm, param_codes.common_Name, result.result_qualifier, result.result_value, result.result_ units FROM ((sites INNER JOIN sample ON sites.site_id = sample.site_id) INNER JOIN result ON sample.sample_id $=$ result.sample_id) INNER JOIN param_codes ON result.param_code = param_codes.param_code WHERE $((($ sites.site_ id) $=[$ Enter Site ID to Search $]))$;

\section{Query Results by Site and Parameter Example}

SELECT sites.site_id, sample.dt_tm, param_codes.common_Name, result.result_qualifier, result.result_value, result.result_ units FROM ((sites INNER JOIN sample ON sites.site_id = sample.site_id) INNER JOIN result ON sample.sample_id = result.sample_id) INNER JOIN param_codes ON result.param_code = param_codes.param_code WHERE $((($ sites.site_ id $)=[$ Enter Site ID to Search $])$ AND ((param_codes.common_Name)=[Enter Parameter to Search $]))$;

\section{Query Results by Parameter and Minimum Detection' Value Example}

SELECT sites.site_id, sample.dt_tm, param_codes.common_Name, result.result_qualifier, result.result_value, result.result_ units FROM ((sites INNER JOIN sample ON sites.site_id = sample.site_id) INNER JOIN result ON sample.sample_id = result.sample_id) INNER JOIN param_codes ON result.param_code = param_codes.param_code WHERE (((param_codes. common_Name $)=[$ Enter Parameter to Search] $)$ AND ((result.result_value) $>[$ Enter Minimum Value $])$ );

\footnotetext{
${ }^{1}$ Laboratory reporting level.
} 


\title{
Appendix 5-FGDC-Compliant Metadata Record
}

\author{
Identification_Information: \\ Citation: \\ Citation_Information: \\ Originator: Various sources. \\ Publication_Date: 20090915 \\ Title: sites \\ Geospatial_Data_Presentation_Form: vector digital data \\ Online_Linkage: IIIgskiacwgsnas\gis_projlb8653_dp6\data\Salinityv3.mdb \\ Description:
}

Abstract: The U.S. Geological Survey, in cooperation with the U.S. Army Corps of Engineers, compiled salinity-related water-quality data and information in a geodatabase containing more than 6,000 sampling sites. The geodatabase was designed as a tool for water-resource management and includes readily available digital data sources from the U.S. Geological Survey, U.S. Environmental Protection Agency, New Mexico Interstate Stream Commission, Sustainability of semi-Arid Hydrology and Riparian Areas, Paso del Norte Watershed Council, numerous other State and local databases, and selected databases maintained by the University of Arizona and New Mexico State University. Salinity information was compiled for an approximately 26,000-square-mile area of the Rio Grande Basin from the Rio ArribaSandoval County line, New Mexico, to Presidio, Texas. The geodatabase relates the spatial location of sampling sites with salinity-related water-quality data reported by multiple agencies. The sampling sites are stored in a geodatabase feature class; each site is linked by a relationship class to the corresponding sample and results stored in data tables.

Purpose: These data are for informational purposes only. These data have not received Bureau approval and as such are provisional and subject to revision. The data are released on the condition that neither the U.S. Geological Survey, its cooperators, nor the U.S. Government may be held liable for any damages resulting from its authorized or unauthorized use. Although these data have been processed successfully on a computer system at the U.S. Geological Survey, no warranty expressed or implied is made regarding the accuracy or utility of the data on any other system or for general or scientific purposes, nor shall the act of distribution constitute any such warranty.

Time_Period_of_Content:

Time_Period_Information:

Single_Date/Time:

Calendar_Date: 2009

Currentness_Reference: 1901-2009

Status:

Progress: On-going

Maintenance_and_Update_Frequency: Unknown

Spatial_Domain:

Bounding_Coordinates:

West_Bounding_Coordinate: -107.729762

East_Bounding_Coordinate: -104.246110

North_Bounding_Coordinate: 36.039700

South_Bounding_Coordinate: 29.519630

Keywords:

Theme: 
Theme_Keyword: salinity

Place:

Place_Keyword: Rio Grande Valley

Use_Constraints: These data are for informational purposes only. These data have not received Bureau approval and as such are provisional and subject to revision. The data are released on the condition that neither the U.S. Geological Survey, its cooperators, nor the U.S. Government may be held liable for any damages resulting from its authorized or unauthorized use. Although these data have been processed successfully on a computer system at the U.S. Geological Survey, no warranty expressed or implied is made regarding the accuracy or utility of the data on any other system or for general or scientific purposes, nor shall the act of distribution constitute any such warranty.

Native_Data_Set_Environment: Microsoft Windows XP Version 5.1 (Build 2600) Service Pack 3; ESRI ArcCatalog 9.3.1.3000

Data_Quality_Information:

Lineage:

Process_Step:

Process_Description: Sample information queries were written to identify potential duplicate data based on location and date. Samples were considered duplicate if the site identifier and sample date were the same. If an entire dataset was duplicated elsewhere, the original dataset was used and the duplicate excluded.

Process_Date: Unknown

Process_Step:

Process_Description: To examine duplicates based on proximity, all sites within 30 meters of another site were inspected. If a site was within the 30-meter buffer and was on top of or very close to a USGS site (well or gage), then the USGS site location was given priority and input into the geodatabase. Other methods such as examining well locations with digital orthophoto quarter quadrangles and USGS topographic maps were used to determine the accuracy of the spatial coordinates assigned by an agency or individual.

Spatial_Data_Organization_Information:

Direct_Spatial_Reference_Method:Vector

Point_and_Vector_Object_Information:

SDTS_Terms_Description:

SDTS_Point_and_Vector_Object_Type: Entity point

Point_and_Vector_Object_Count: 6397

Spatial_Reference_Information:

Horizontal_Coordinate_System_Definition:

Geographic:

Latitude_Resolution: 0.000000

Longitude_Resolution: 0.000000

Geographic_Coordinate_Units: Decimal degrees

Geodetic_Model:

Horizontal_Datum_Name: North American Datum of 1983

Ellipsoid_Name: Geodetic Reference System 80

Semi-major_Axis: 6378137.000000

Denominator_of_Flattening_Ratio: 298.257222

Entity_and_Attribute_Information:

Detailed_Description:

Entity_Type: 
Entity_Type_Label: sites

Attribute:

Attribute_Label: OBJECTID

Attribute_Definition: Internal feature number.

Attribute_Definition_Source: ESRI

Attribute_Domain_Values:

Unrepresentable_Domain: Sequential unique whole numbers that are automatically generated. Attribute:

Attribute_Label: SHAPE

Attribute_Definition: Feature geometry.

Attribute_Definition_Source: ESRI

Attribute_Domain_Values:

Unrepresentable_Domain: Coordinates defining the features.

Attribute:

Attribute_Label: site_id

Attribute_Definition: Site name.

Attribute:

Attribute_Label: site_description

Attribute:

Attribute_Label: type_code

Attribute_Definition: Site type.

Attribute:

Attribute_Label: lat_dd

Attribute_Definition: Reported site latitude in decimal degrees.

Attribute:

Attribute_Label: lon_dd

Attribute_Definition: Reported site longitude in decimal degrees.

Attribute:

Attribute_Label: h_datum

Attribute_Definition: Reported site horizontal datum.

Attribute:

Attribute_Label: alt_ft

Attribute_Definition: Reported site altitude (in feet).

Attribute:

Attribute_Label: v_datum

Attribute_Definition: Reported vertical datum.

Attribute:

Attribute_Label: site_comments

Attribute_Definition: Comments about the site.

Attribute:

Attribute_Label: source

Attribute_Definition: Source of the site data.

Attribute:

Attribute_Label: primary_site

Attribute_Definition: Primary site name.

Detailed_Description:

Entity_Type: 
Entity_Type_Label: site2sample

Distribution_Information:

Resource_Description: Downloadable Data

Metadata_Reference_Information:

Metadata_Date: 20090929

Metadata_Contact:

Contact_Information:

Contact_Organization_Primary:

Contact_Organization: U.S. Geological Survey

Contact_Person: Public Information Officer

Contact_Address:

Address_Type: mailing and physical address

Address: 1505 Ferguson Lane

City: Austin

State_or_Province: Texas

Postal_Code: 78754

Country: USA

Contact_Voice_Telephone: 512-927-3500

Contact_Facsimile_Telephone: 512-927-3590

Contact_Electronic_Mail_Address: gs-w-txpublic-info@usgs.gov

Metadata_Standard_Name: FGDC Content Standards for Digital Geospatial Metadata

Metadata_Standard_Version: FGDC-STD-001-1998

Metadata_Time_Convention: local time

Metadata_Extensions:

Online_Linkage: http://www.esri.com/metadata/esriprof80.html

Profile_Name: ESRI Metadata Profile 
Blank Page 
